\title{
Towards the implementation of a system for manuscript editor certification
}

\author{
Hyun Jung $\mathrm{Yi}^{1}$, Hye-Min $\mathrm{Cho}^{2}$, Hee Kyung Chung ${ }^{2}$, Hwan Tae Ahn², Myung-Soon Kim², \\ Yoon Joo Seo ${ }^{4}$ \\ ${ }^{1}$ Medical Library, Hangyang University Guri Hospital, Guri; ${ }^{2}$ Infolumi, Seongnam; ${ }^{3}$ Electronics and Telecommunications Research \\ Institute, Daejeon; ${ }^{4}$ Medrang Inc., Seoul, Korea
}

Abstract

Style and format are important criteria for evaluating a journal and indexing it in major databases. In Korean science, technology, and medical journals, interest in manuscript editing has increased over the past seven to eight years, and the responsibilities of manuscript editors have expanded as well. However, since no clear standards for the roles and qualifications for manuscript editors are yet available, a formal certification system is needed to establish appropriate standards and to provide professional training. To identify ways of developing a manuscript editor certification program in Korea, this study investigated similar certification programs in and outside the country and surveyed 195 Korean editors, manuscript editors, publishers, and medical librarians. The survey revealed that manuscript editors were necessary (mean score of 4.38 on a five-point Likert scale, with a score of 5 indicating strong agreement), and that their main contributions were efficiently managing the editorial board, improving the accuracy of references, and accelerating the editing process. The respondents were also positive about the possibility of implementing a manuscript editor certification; $45.1 \%$ showed interest in becoming certified, and $47.1 \%$ reported interest in hiring a certified manuscript editor. Regarding the system for issuing certification, respondents favored a professional training course (53.1\%), validation of work experience (27.1\%), or an examina-

Accepted: January 12,2016

Correspondence to Hye-Min Cho infolumi.cho@gmail.com

ORCID

Hyun Jung Yi

http://orcid.org/0000-0003-0663-4373 Hye-Min Cho

http://orcid.org/0000-0002-1672-0200

Hee Kyung Chung

http://orcid.org/0000-0002-1380-6965

Hwan Tae Ahn

http://orcid.org/0000-0001-5221-990X

Myung-Soon Kim

http://orcid.org/0000-0001-5757-1574

Yoon Joo Seo

http://orcid.org/0000-0002-0202-8352 tion (16.8\%). This study concludes that it is essential to establish a formal certification program to train manuscript editors properly, and an examination system is the most efficient and suitable method for managing the certification process.

Keywords

Manuscript editor; Certification; Korea

\section{Introduction}

Style and format are important criteria when a journal is evaluated for indexing in international databases such as the Science Citation Index Expanded (SCIE) or Scopus, as well as in Korean

This is an open access article distributed under the terms of the Creative Commons Attribution Non-Commercial License (http://creativecommons.org/ licenses/by-nc/3.0/), which permits unrestricted non-commercial use, distribution, and reproduction in any medium, provided the original work is properly cited. 
databases such as the Korean Citation Index of National Research Foundation. Thus, the editorial boards of Korean science, technology, and medicine (STM) journals have displayed an increasing interest in manuscript editing over the last seven to eight years, and manuscript editors have been actively working in the field; however, no formal degree programs or clear standards for qualification exist for manuscript editors. In the United States, the Board of Editors in the Life Sciences (BELS) has administered a certification program since 1991, and associations such as the American Medical Writers Association (AMWA) and the Council of Science Editors (CSE) have recently implemented new certification programs.

In order to increase the quality and quantity of manuscript editors in Korea, it is crucial to develop effective ways to review the qualifications of manuscript editors and to establish a certification program well-adapted to the current needs of Korean journals. The aim of this research was to propose detailed plans for the establishment of a manuscript editor certification program suitable for Korea.

\section{Methods}

This study applied two analytical models to identify the features of an effective certification program that would be well- adapted to Korean journals. First, we reviewed various international manuscript editing certification programs as well as two Korean certification programs. Second, we conducted a survey investigating the opinions of journal editors and manuscript editors in the STM field.

\section{Certification programs in and outside Korea}

For this study, several international and domestic certification programs, either directly related to manuscript editors or otherwise relevant, were selected and investigated. Certification and certificate programs abroad (the distinction between certificate and certification programs is based on AMWA classification criteria; http://www.amwa.org/certification_differences) were represented by BELS, AMWA, and CSE programs. In these certification programs, journal editors and manuscript editors in STM fields are primarily responsible for training new-coming editors and manuscript editors. In Korea, however, no certification programs related to manuscript editing exist. Thus although they are not directly related to the topic, two Korean certification programs were chosen for analysis in this study: one was the Korean Medical Librarian certification program administered by the Korean Medical Library Association, and the other was the Korean Language Teacher certification system run by the Ministry of Culture, Sports, and Tourism.

Table 1. Survey questions

\begin{tabular}{|c|c|c|c|}
\hline Topic & Question & Question type & Remark \\
\hline Characteristic of respondents & $\begin{array}{l}\text { Affiliation } \\
\text { Job title } \\
\text { Age } \\
\text { Journal editing experience }\end{array}$ & $\begin{array}{l}\text { Closed } \\
\text { Closed } \\
\text { Open } \\
\text { Open }\end{array}$ & $\begin{array}{l}\text { Single-choice } \\
\text { Single-choice } \\
\text { Numerical response } \\
\text { Numerical response }\end{array}$ \\
\hline Journal characteristic & $\begin{array}{l}\text { Subject area } \\
\text { Indexed databases }\end{array}$ & $\begin{array}{l}\text { Closed } \\
\text { Closed }\end{array}$ & $\begin{array}{l}\text { Single-choice } \\
\text { Multiple-choice }\end{array}$ \\
\hline Reason for needing manuscript editors & $\begin{array}{l}\text { Efficient management of the editorial board } \\
\text { Acceleration of the journal editing process } \\
\text { Accuracy of the journal references } \\
\text { Accuracy of the overall paper (excluding references) } \\
\text { Responding to journal evaluations } \\
\text { Indexing of the journal in prominent international databases } \\
\text { Overall need for manuscript editors }\end{array}$ & $\begin{array}{l}\text { Closed } \\
\text { Closed } \\
\text { Closed } \\
\text { Closed } \\
\text { Closed } \\
\text { Closed } \\
\text { Closed }\end{array}$ & $\begin{array}{l}\text { Single-choice } \\
\text { Single-choice } \\
\text { Single-choice } \\
\text { Single-choice } \\
\text { Single-choice } \\
\text { Single-choice } \\
\text { Single-choice }\end{array}$ \\
\hline $\begin{array}{l}\text { Manuscript editor qualification } \\
\text { and certification }\end{array}$ & $\begin{array}{l}\text { Educational qualifications for a manuscript editor } \\
\text { Experience qualifications when hiring a manuscript editor } \\
\text { Importance of manuscript editor eligibility criteria } \\
\text { Acquiring manuscript editor certification } \\
\text { Hiring a certified manuscript editor } \\
\text { Acquisition requirements for manuscript editor certification } \\
\text { Manuscript editor recertification requirements }\end{array}$ & $\begin{array}{l}\text { Closed } \\
\text { Closed } \\
\text { Closed } \\
\text { Closed } \\
\text { Closed } \\
\text { Closed } \\
\text { Closed }\end{array}$ & $\begin{array}{l}\text { Single-choice } \\
\text { Single-choice } \\
\text { Rank selection } \\
\text { Single-choice } \\
\text { Single-choice } \\
\text { Single-choice } \\
\text { Single-choice }\end{array}$ \\
\hline Other opinion & $\begin{array}{l}\text { Opinions on implementing the manuscript editor certification program } \\
\text { Opinions on difficulties in journal publication and management }\end{array}$ & $\begin{array}{l}\text { Open } \\
\text { Open }\end{array}$ & $\begin{array}{l}\text { Short answer } \\
\text { Short answer }\end{array}$ \\
\hline
\end{tabular}




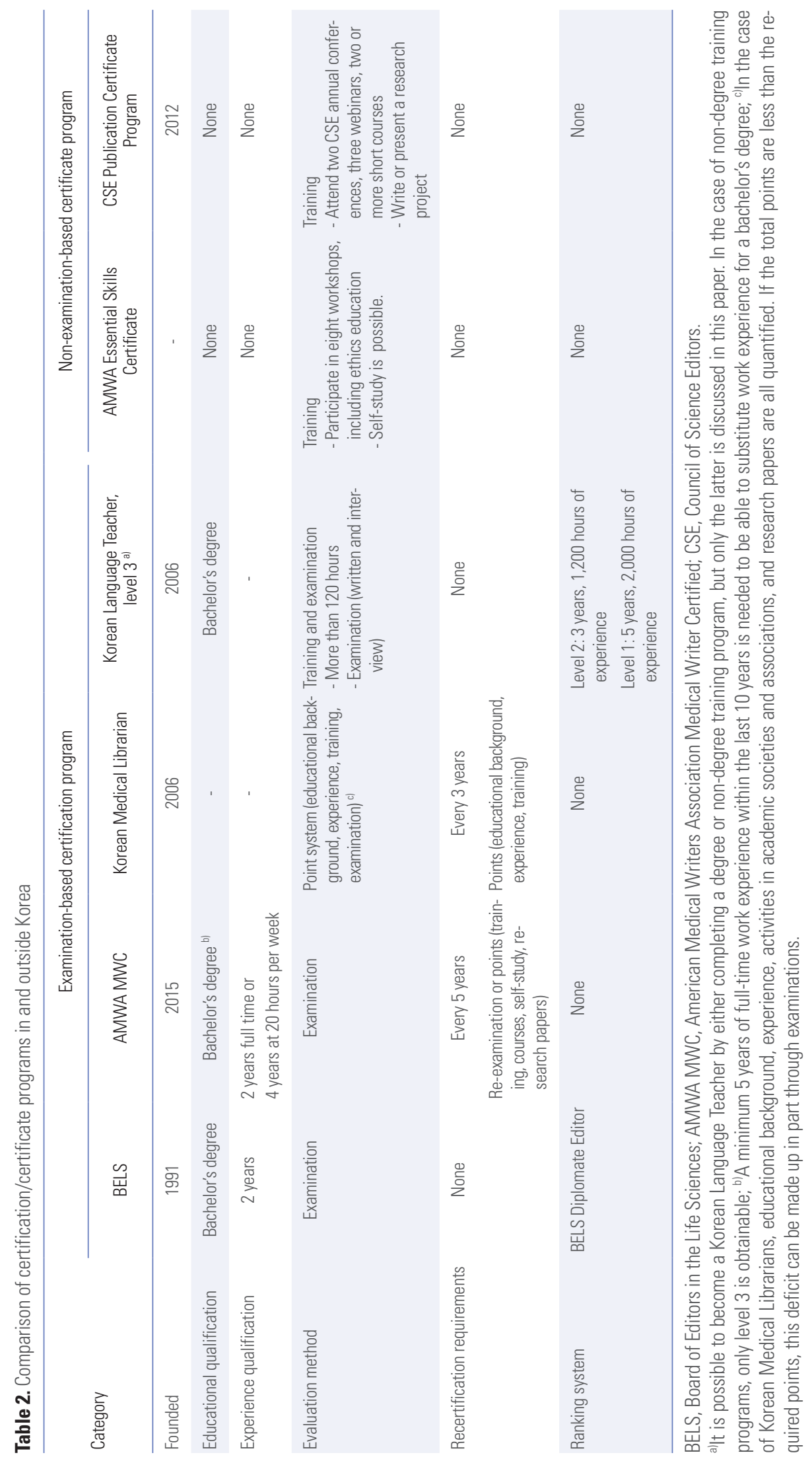




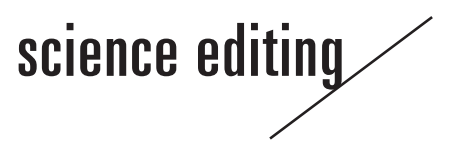

This study investigated the certification program details available on all five associations' homepages [1-5], with a particular focus on the qualifications for acquiring certification, detailed procedures for qualifying and applying, the recertification policy, and the system for advancing to a higher level of certification.

\section{Survey}

A survey was conducted between June 10 and July 9, 2015 to solicit opinions regarding a manuscript editor certification program suitable for Korea. The survey was distributed online to the members of the Korean Council of Science Editors (KCSE) and the Korean Medical Library Association, and was also administered to the participants at KCSE workshop on July 3, 2015. The 198 survey participants were editors, manuscript editors, librarians, publishing professionals, and staff members of academic societies. Three of the 198 surveys were excluded due to incomplete information, resulting in a total of 195 that were analyzed. The survey questions are presented in Table 1.

SPSS ver. 21.0 (IBM Co., Armonk, NY, USA) was used to analyze the results. First, frequency analysis was performed to determine the characteristics of the respondents and the journals. The characteristics of the respondents were further classified based on the subject area and the status of the journals. Second, descriptive statistics and frequency analysis were conducted on the responses to each survey question. Analysis of variance was conducted to analyze how responses differed according to groups defined by affiliation, position, age, experience, and subject area. Third, cross-tabulation analysis was performed to analyze how the specific roles of the manuscript editors affected overall perceptions of the necessity for manuscript editors. In addition, regression analysis was conducted to identify the most important factors contributing to the overall need for a manuscript editor. Fourth, the results of open-ended questions in the survey were analyzed to perform an in-depth investigation of the respondents' opinions on journal management in general and manuscript editors in particular.

\section{Results}

Results from Korea and abroad

The results of our investigation regarding various types of international and Korean certification programs are shown in Table 2. Most examination-based certifications were found to require a bachelor's degree and two years of full-time work experience, as well as requiring an individual to pass an examination. The medical librarian program issues certifications on a point system with no specific educational or work experience requirements; however, the requirements are fundamentally no different from those of other certification pro- grams because the medical librarian certification is only issued to those who have obtained a librarian certification from college and worked at a medical library subsequently.

On the other hand, there are certificate programs based on a combination of proper training and conference participation without an examination in AMWA Essential Skills Certificate and CSE Publication Certificate Program.

In recertification, the process does not include a separate examination but requires continuing education in most cases. Only two associations had ranked levels of certification system. In the case of BELS, if a candidate has more than six years of total editing experience and two years have passed since the certification was obtained, the individual can apply to be a BELS Diplomate Editor, the evaluation for which is based on editing experience and two essays. The Korean Language Teacher Education Center uses a three-tier ranking system, which requires 1,200 hours of experience to move from level 1 to level 2 and 2,000 hours of experience to advance to level 3. These institutions, which adopt a certification ranking system, generally have either a long history or a large pool of certified editors.

Survey results

\section{Characteristics of the respondents}

The characteristics of the respondents are presented in Table 3.

Table 3. Characteristics of respondents ( $n=195)$

\begin{tabular}{|c|c|c|}
\hline & Category & №. $(\%)$ \\
\hline Affiliation & $\begin{array}{l}\text { Academic society } \\
\text { Research institution (including universities) } \\
\text { Library } \\
\text { Publication industry } \\
\text { Other }\end{array}$ & $\begin{array}{l}130(66.7) \\
27(13.8) \\
17(8.7) \\
11(5.6) \\
10(5.1)\end{array}$ \\
\hline Job title & $\begin{array}{l}\text { Editor-in-chief, associate/assistant editor } \\
\text { Editorial board member } \\
\text { Manuscript editor } \\
\text { Reviewer } \\
\text { Librarian } \\
\text { Typesetter } \\
\text { Copy editor } \\
\text { Editorial assisitant }\end{array}$ & $\begin{array}{r}81(41.5) \\
26(13.3) \\
36(18.5) \\
4(2.1) \\
16(8.2) \\
8(4.1) \\
5(2.6) \\
19(9.7)\end{array}$ \\
\hline Age (yr) & $\begin{array}{l}20 s \\
30 s \\
40 s \\
\geq 50 s \\
\text { No response }\end{array}$ & $\begin{array}{l}18(9.2) \\
51(26.2) \\
71(36.4) \\
53(27.2) \\
2(1.0)\end{array}$ \\
\hline Experience (yr) & $\begin{array}{l}<1 \\
1-2 \\
3-4 \\
5-6 \\
\geq 7\end{array}$ & $\begin{array}{l}32(16.4) \\
51(26.2) \\
35(17.9) \\
27(13.8) \\
50(25.6)\end{array}$ \\
\hline
\end{tabular}


Most of the respondents (66.7\%) were affiliated with an academic society, and editor-in-chief/associate/assistant editors and manuscript editors were the most common job titles (41.5\% and $18.5 \%$, respectively). The journals in which the respondents were involved encompassed a wide range of disciplines, with $45.6 \%$ in the health sciences, $25.6 \%$ in the engineering sciences, $12.3 \%$ in the natural sciences, $11.8 \%$ in agricultural and fisheries sciences, and $4.6 \%$ in interdisciplinary subjects. A multiple-choice question evaluated the indexing status in international databases of the journal with which the respondents were affiliated. Of the journals, $25.6 \%$ were found to be indexed in SCIE and 34.9\% were indexed in Scopus.

\section{Perceived need for manuscript editors}

As shown in Table 4, the survey results reveal that many respondents recognized the need for manuscript editors (mean score of 4.38 on a five-point Likert scale, with a score of 5 indicating that strong agreement that manuscript editors were necessary). No differences in response were found by affiliation, position, age, experience, or subject area.

Table 5 presents the responses to six possible reasons for needing manuscript editors. Numerous respondents indicated that the most important reasons for requiring manuscript editors were efficient management of the editorial board, accuracy of the references, and acceleration of the editing process. However, for all six reasons, many more respondents agreed (reporting agreement or strong agreement: $88.7 \%, 90.8 \%$, $84.6 \%, 86.6 \%, 86.2 \%$, and $77.9 \%$, respectively) than disagreed (reporting disagreement and strong disagreement: $2.6 \%, 2.6 \%$, $4.1 \%, 3.6 \%, 3.6 \%$, and $3.6 \%$, respectively). Therefore, we found strong recognition of the need for manuscript editors.

Our results suggest that affiliation, position, age, and experience had no effect on the recognition of the need for manuscript editors. However, some differences were found according to subject area; for example, in the health sciences, accuracy of the references was reported to be the most important reason for needing manuscript editors (health sciences mean, 4.54; overall mean, 4.34).

In order to identify which factors affected the overall need for a manuscript editor, stepwise regression analysis was conducted on the following parameters:efficient management of the editorial board, acceleration of the editing process, accu-

Table 4. Perceived need for manuscript editors depending on the characteristics of the respondents ${ }^{\mathrm{a}}$

\begin{tabular}{|c|c|c|c|c|}
\hline & Category & Mean & SD & $F / P$ \\
\hline Affiliation & $\begin{array}{l}\text { Academic society } \\
\text { Research institution (including university) } \\
\text { Library } \\
\text { Publication industry } \\
\text { Others }\end{array}$ & $\begin{array}{l}4.35 \\
4.37 \\
4.35 \\
4.82 \\
4.30\end{array}$ & $\begin{array}{l}0.756 \\
0.839 \\
0.996 \\
0.405 \\
0.483\end{array}$ & $2.055 / 0.088$ \\
\hline Job title & $\begin{array}{l}\text { Editor-in-chief, associate/assistant editor } \\
\text { Editorial board member, reviewer } \\
\text { Manuscript editor } \\
\text { Librarian } \\
\text { Typesetter, copy editor, editorial assistant }\end{array}$ & $\begin{array}{l}4.46 \\
4.27 \\
4.61 \\
4.31 \\
4.06\end{array}$ & $\begin{array}{l}0.725 \\
0.740 \\
0.549 \\
1.014 \\
0.878\end{array}$ & $0.629 / 0.642$ \\
\hline Age (yr) & $\begin{array}{l}20 s \\
30 s \\
40 s \\
\geq 50 s\end{array}$ & $\begin{array}{l}4.39 \\
4.43 \\
4.30 \\
4.45\end{array}$ & $\begin{array}{l}0.608 \\
0.700 \\
0.782 \\
0.845\end{array}$ & $0.566 / 0.638$ \\
\hline Experience (yr) & $\begin{array}{l}<1 \\
1-2 \\
3-4 \\
5-6 \\
\geq 7\end{array}$ & $\begin{array}{l}4.38 \\
4.43 \\
4.34 \\
4.52 \\
4.28\end{array}$ & $\begin{array}{l}0.833 \\
0.575 \\
0.725 \\
0.580 \\
0.991\end{array}$ & $1.791 / 0.132$ \\
\hline Subject area ${ }^{\text {b) }}$ & $\begin{array}{l}\text { Health science } \\
\text { Engineering science } \\
\text { Natural science } \\
\text { Agricultural and fisheries science }\end{array}$ & $\begin{array}{l}4.52 \\
4.16 \\
4.38 \\
4.26\end{array}$ & $\begin{array}{l}0.659 \\
0.866 \\
0.924 \\
0.752\end{array}$ & $0.618 / 0.604$ \\
\hline Total & & 4.38 & 0.766 & \\
\hline
\end{tabular}

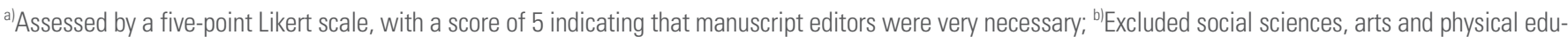
cation, and interdisciplinary studies. 
Table 5. Perception of needs for manuscript editors on a five-point scale

\begin{tabular}{|c|c|c|c|c|c|c|}
\hline Category & Strongly disagree & Disagree & Undecided & Agree & Strongly agree & Mean \pm SD \\
\hline Efficient management of the editorial board & $1(0.5)$ & $4(2.1)$ & $17(8.7)$ & 64 (32.8) & $109(55.9)$ & $4.42 \pm 0.78$ \\
\hline Acceleration of the editing process & 0 & $5(2.6)$ & $13(6.7)$ & $75(38.5)$ & $102(52.3)$ & $4.41 \pm 0.73$ \\
\hline Accuracy of the references & $2(1.0)$ & $6(3.1)$ & $22(11.3)$ & $60(30.8)$ & $105(53.8)$ & $4.33 \pm 0.87$ \\
\hline Accuracy of the overall paper & 0 & $7(3.6)$ & $19(9.7)$ & $73(37.4)$ & $96(49.2)$ & $4.32 \pm 0.80$ \\
\hline Responding to journal evaluations & $3(1.5)$ & $4(2.1)$ & $20(10.3)$ & $91(46.7)$ & $77(39.5)$ & $4.21 \pm 0.82$ \\
\hline Indexing of the journal in prominent databases & $2(1.0)$ & $5(2.6)$ & $36(18.5)$ & $73(37.4)$ & $79(40.5)$ & $4.14 \pm 0.88$ \\
\hline Overall need & & & & & & $4.38 \pm 0.77$ \\
\hline
\end{tabular}

Values are presented as number (\%) unless otherwise indicated.

Table 6. Factors affecting the need for manuscript editors

\begin{tabular}{|c|c|c|c|c|c|c|c|c|}
\hline Dependent variable & Independent variable & $\begin{array}{c}\text { Non-standardized } \\
\text { coefficient (B) }\end{array}$ & $\begin{array}{l}\text { Standard } \\
\text { deviation }\end{array}$ & $\begin{array}{c}\text { Standardized } \\
\text { coefficient }\end{array}$ & $\mathrm{t}$ & P-value & Durbin-Watson & $\mathrm{R}^{2}$ \\
\hline \multirow[t]{7}{*}{ Overall need } & Constant & -0.017 & 0.192 & & -0.088 & 0.930 & 2.008 & 0.755 \\
\hline & $\begin{array}{l}\text { Efficient } \\
\text { management }\end{array}$ & 0.181 & 0.056 & 0.184 & 3.208 & 0.002 & & \\
\hline & Speed & 0.256 & 0.058 & 0.243 & 4.430 & 0.000 & & \\
\hline & $\begin{array}{l}\text { Accuracy of the } \\
\text { references }\end{array}$ & 0.038 & 0.039 & 0.043 & 0.966 & 0.335 & & \\
\hline & $\begin{array}{c}\text { Accuracy of the } \\
\text { overall paper }\end{array}$ & 0.192 & 0.050 & 0.199 & 3.838 & 0.000 & & \\
\hline & $\begin{array}{l}\text { Responding to } \\
\text { journal evaluations }\end{array}$ & 0.083 & 0.051 & 0.089 & 1.625 & 0.106 & & \\
\hline & $\begin{array}{l}\text { Indexing of the } \\
\text { journal in databases }\end{array}$ & 0.272 & 0.045 & 0.312 & 6.067 & 0.000 & & \\
\hline
\end{tabular}

racy of the references, accuracy of the overall paper, handling journal accreditation, and indexing of the journal in prominent databases. The overall need for a manuscript editor was identified as the dependent variable, while the other six variables were the independent variables (Table 6).

When the six independent variables were analyzed, their standardized coefficients were as follows, in descending order: journal indexing in databases, 0.312; acceleration of the editing process, 0.243; overall accuracy of the paper, 0.199; efficient management of the editorial board, 0.184; responding to journal evaluations, 0.089 ; and accuracy of the references, 0.043. The need for a manuscript editor was the highest among journals pursuing indexing in prominent databases.

\section{Qualifications of manuscript editors}

Educational qualifications: When asked what level of education is necessary to carry out the role of a manuscript editor, 85 participants (43.6\%) responded that a bachelor's degree or above was required. Seventy-five participants (38.5\%) identi- fied a need for a master's degree or above, and 22 participants $(11.3 \%)$ stated that a doctoral degree or above was required (Table 7). Cross-tabulation analysis was conducted to identify differences in opinion regarding educational qualifications according to affiliation, job title, age, subject area, and work experience (Table 7). Differences in responses by affiliation, job title, age, and subject area were statistically significant at the $\mathrm{P}=0.01$ level. However, work experience was not found to have a statistically significant effect on opinions regarding educational qualifications.

Experience qualifications: When asked how much work experience a manuscript editor should have to be hired, 85 respondents $(43.6 \%)$ responded that one to three years were necessary, $55(28.2 \%)$ responded that three to five years were necessary, 24 respondents (12.3\%) indicated that prior experience was irrelevant in their opinion, and 18 respondents (9.2\%) indicated that five to seven years of experience were suitable.

Importance of eligibility criteria: The survey asked respon- 
Table 7. Opinions regarding the required educational background of manuscript editors

\begin{tabular}{|c|c|c|c|c|c|c|c|c|}
\hline & Category & Irrelevant & $\begin{array}{l}\text { Associate's } \\
\text { degree }\end{array}$ & $\begin{array}{c}\text { Bachelor's } \\
\text { degree }\end{array}$ & $\begin{array}{c}\text { Master's } \\
\text { degree }\end{array}$ & $\begin{array}{c}\text { Doctoral } \\
\text { degree }\end{array}$ & Total & $\chi^{2} / P$ \\
\hline Total & & $6(3.1)$ & $7(3.6)$ & $85(43.6)$ & 75 (38.5) & $22(11.3)$ & 195 & \\
\hline Affiliation & Non-academic society & $1(1.5)$ & $1(1.5)$ & $40(61.5)$ & $19(29.2)$ & $4(6.2)$ & 65 & \\
\hline \multirow[t]{4}{*}{ Job title } & Editor-in-chief, associate/assistant editor & $1(1.2)$ & $2(2.5)$ & $24(29.6)$ & $42(51.9)$ & $12(14.8)$ & 81 & $46.489 / 0.000^{* *}$ \\
\hline & Manuscript editor & 0 & $1(2.8)$ & $22(61.1)$ & $12(33.3)$ & $1(2.8)$ & 36 & \\
\hline & Librarian & 0 & 0 & $12(75.0)$ & $4(25.0)$ & 0 & 16 & \\
\hline & Typesetter, copy editor, editorial assistant & $3(9.4)$ & $3(9.4)$ & $20(62.5)$ & $3(9.4)$ & $3(9.4)$ & 32 & \\
\hline \multirow[t]{3}{*}{ Age (yr) } & $20 \mathrm{~s}$ & $1(5.6)$ & 0 & $11(61.1)$ & $4(22.2)$ & $2(11.1)$ & 18 & $28.370 / 0.005^{* *}$ \\
\hline & $30 \mathrm{~s}$ & $1(2.0)$ & $3(5.9)$ & $33(64.7)$ & $10(19.6)$ & $4(7.8)$ & 51 & \\
\hline & Subtotal & $6(3.1)$ & $7(3.6)$ & $83(43.0)$ & 75 (38.9) & $22(11.4)$ & $193^{\text {a) }}$ & \\
\hline \multirow[t]{5}{*}{ Experience (yr) } & $<1$ & $1(3.1)$ & 0 & $20(62.5)$ & $9(28.1)$ & $2(6.3)$ & 32 & 22.388/0.131 \\
\hline & $1-2$ & $1(2.0)$ & $1(2.0)$ & $20(39.2)$ & $20(39.2)$ & $9(17.6)$ & 51 & \\
\hline & $3-4$ & $2(5.7)$ & 0 & $18(51.4)$ & $10(28.6)$ & $5(14.3)$ & 35 & \\
\hline & $5-6$ & 0 & $1(3.7)$ & $10(37.0)$ & $13(48.1)$ & $3(11.1)$ & 27 & \\
\hline & $\geq 7$ & $2(4.0)$ & $5(10.0)$ & $17(34.0)$ & $23(46.0)$ & $3(6.0)$ & 50 & \\
\hline \multirow[t]{3}{*}{ Subject area } & Health science & $2(2.2)$ & $4(4.5)$ & $46(51.7)$ & 35 (39.3) & $2(2.2)$ & 89 & $28.827 / 0.004^{* *}$ \\
\hline & Engineering science & $3(6.0)$ & $1(2.0)$ & $23(46.0)$ & $19(38.0)$ & $4(8.0)$ & 50 & \\
\hline & Natural science & 0 & $2(8.3)$ & 8 (33.3) & 8 (33.3) & $6(25.0)$ & 24 & \\
\hline
\end{tabular}

Values are presented as numbers (\%).

a) Excluding two missing values; ${ }^{b}$ Excluding social sciences, arts and physical education, and interdisciplinary studies. ${ }^{* *} \mathrm{P}<0.01$.

dents to rank the three most important criteria for becoming a manuscript editor. In the ranking analysis, the most important response was weighted as 3 points, the second most important response was weighted as 2 points, and the third most important response was weighted as 1 point (Table 8). Subject comprehension level (i.e., knowledge related to the subject area) ranked first with a total score of 330, the ability to document sources ranked second with a score of 321 , and journal publication knowledge ranked third with a score of 207. Document editing ranked fourth at 130 points, language skills ranked fifth at 111 points, and the highest level of education and the ability to analyze and interpret statistics ranked sixth and seventh, respectively. Overall, the ability to document sources and journal publication knowledge were found to be valued, and understanding of the journal content was found to be strongly desired.

\section{Manuscript editor certification program}

Acquiring manuscript editor certification or hiring a manuscript editor: A five-point Likert scale, ranging from strongly disinterested to highly interested, was used to investigate whether or not there would be demand for obtaining certification or for hiring a certified editor if the KCSE implemented a manuscript editor certification program. Each respondent was allowed to answer only one of these two questions. Regarding their interest in obtaining manuscript editor certification, $45.1 \%$ of respondents stated that they would be interested in doing so (responses of highly interested or interested) and $31.3 \%$ indicated that they would not be interested (responses of strongly or somewhat disinterested). These results indicate that the participants were inclined to become certified. Regarding their intention to hire certified manuscript editors, a much higher percentage (47.1\%) intended to do so 


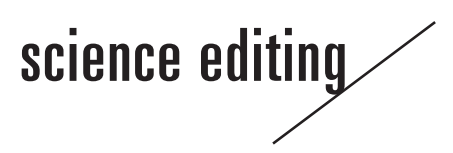

Hyun Jung Yi et al

Table 8. Eligibility criteria for manuscript editors ( $n=195$ )

\begin{tabular}{|c|c|c|c|c|c|}
\hline Category & Most important & Second most important & Third most important & Total & Overall ranking \\
\hline Highest degree & $5(2.6)$ & $7(3.6)$ & $7(3.6)$ & 36 & 6 \\
\hline Language skill & $13(6.7)$ & $23(11.8)$ & 26 (13.3) & 111 & 5 \\
\hline Comprehension level of the journal subject area & $78(40.0)$ & $33(16.9)$ & $30(15.4)$ & 330 & 1 \\
\hline Source documentation skill & $52(26.7)$ & $68(34.9)$ & $29(14.9)$ & 321 & 2 \\
\hline Journal publication knowledge & $25(12.8)$ & $39(20.0)$ & $54(27.7)$ & 207 & 3 \\
\hline Statistical analysis and interpretation skill & $1(0.5)$ & $5(2.6)$ & $22(11.3)$ & 35 & 7 \\
\hline Editing skill & $21(10.8)$ & $20(10.3)$ & $27(13.8)$ & 130 & 4 \\
\hline
\end{tabular}

Values are presented as number (\%).

(responses of interested or highly interested) than did not (strongly or somewhat disinterested), comprising only $13.4 \%$ of the participants. In general, an inclination was found to hire those who have satisfied the eligibility criteria to become a manuscript editor.

Acquisition requirements for manuscript editor certification: In order to identify opinions regarding the eligibility criteria for obtaining manuscript editor certification, a multiplechoice question was asked. Most respondents (53.1\%) supported completion of professional training courses, $27.1 \%$ supported validation of prior work experience, and $16.8 \%$ supported an examination for certification acquisition.

Manuscript editor recertification requirements: When asked about the most suitable recertification criteria if the KCSE were to implement a certification program, $65.1 \%$ of respondents stated that recertification should be granted for taking training courses on a regular basis. Next, $19.5 \%$ indicated that recertification was unnecessary and that once acquired, the certification should be permanent; and $13.3 \%$ supported taking training courses on a regular basis and then taking an exam for recertification. These responses made it clear that training was generally considered important; however, no statistically significant differences were observed among responses according to the characteristics of the respondents or the journals they were affiliated with.

Opinions on implementing the manuscript editor certification program: In order to perform an in-depth analysis of the respondents' opinions regarding the need for manuscript editors and certification programs, the survey included openended questions where the respondents could answer freely. The responses were compiled and sorted into groups by response, allowing for quantification within groups. However, some responses were quite lengthy and thoughtful, revealing important qualitative features that could not have been measured through statistical analysis.

Frequency analysis was conducted on the 85 short-answer responses that remained after 110 invalid responses were excluded. The most prevalent opinion was that the program should make an effort to have credibility (22 responses, $25.9 \%$ ), followed by the opinion that the program needs to be engaging and interesting (19 responses, 22.4\%). Eighteen responses $(21.2 \%)$ stated that there was no need for certification. Some additional responses included the opinions that hiring manuscript editors is difficult due to a lack of funding (six responses, $7.1 \%$ ), that training is more important than certification (five responses, 2.6\%), and that long training hours are stressful (four opinions, $2.1 \%$ ). Respondents also stated that manuscript editors could be trained by institutions, not necessarily through certification programs, that standards for application eligibility needed tobe lowered, that the role of the manuscript editor needed to be standardized, that it would be best to hire librarians with a master's degree or above, that those with foreign manuscript editor certification should automatically receive a KCSE certification, that the certification acquisition process should allow telecommuting, and that separate certifications should exist for Korean-language and English-language journals.

\section{Discussion}

The purpose of this study was to identify methods for establishing a manuscript editor certification program suited to Korea, in order to improve the quality and quantity of manuscript editors in Korea. The results of our survey indicate that the majority of individuals involved in journal editing and publication in Korea recognized the need for manuscript editors and showed support for a manuscript editor certification program. This clearly shows that certified manuscript editors are in demand. Detailed proposals regarding the implementation of such a program, training, and examinations are presented below. 
Implementation of a certification program

Recently, international efforts have been made to establish manuscript editor certification programs in order to improve the quality of manuscript editors. AMWA has been running non-examination-based certificate program (AMWA Essential Skills Certificate) for a long time, and since 2015, AMWA has also been issuing certification based on an examination (MWC, Medical Writer Certified). CSE Publication Certificate Program implemented a similar non-examination-based certificate program in 2012. BELS and AMWA MWC have been issuing certification based on examinations, while the CSE Publication Certificate Program and AMWA Essential Skills Certificate have been running non-examination-based certificate programs requiring only a designated period of training.

Domestic certification programs include that of the Korean Medical Library Association, which has been issuing certification based on an examination since 2006, and that of the National Institute of Korean Language that has been issuing Korean Language Teacher certification involving a set period of training as well as an examination for those who have not received a standard college degree.

Our survey found that the most popular methods for certification were professional training courses $(53.1 \%$ of responses), validation for previous experience $(27.1 \%)$, and a certification examination $(16.8 \%)$. These findings indicate that respondents preferred training and experience to an examination as a basis for issuing a manuscript editor certification.

Both Korean and international programs involve a distinction between examination-based certification programs, which are issued based on an examination as well as the candidate's previous background and/or training, and non-examination-based certificate programs, which do not require examinations. If a manuscript editor certification program is implemented in Korea, it should be implemented gradually, first starting as a non-examination-based certificate program, then advancing to an examination-based phase after two to three years. Because the need for manuscript editors is currently increasing, a certification system based on examination would be the most time- and labor-efficient method of quickly cultivating professional manuscript editors.

\section{Eligibility for application and levels of certification}

In order to apply for certification, the minimum requirements would be to have a bachelor's degree or above and two years or more of full-time work experience. However, if an applicant does not have a college degree, full-time work experience of equivalent length should be substitutable for a degree and vice versa. With regard to certification levels, few individuals are expected to initially apply to the manuscript editor certification program, so a single level of certification would seem to be suitable. Thus, only one level should be adopted initially, and as the number of certified manuscript editors increases, a ranked levels of certification based on experience can be considered.

\section{Training curriculum and examinations}

When asked to identify the knowledge required of a manuscript editor, the responses from most to least frequent were as follows: comprehension of the subject (i.e., knowledge related to the subject area), the ability to document sources, journal publication knowledge, document editing ability, language skills, the highest level of education, and the ability to analyze and interpret statistics.

BELS started its certification program in 1991. Its examination tests English grammar skills (grammar, punctuation, mechanics, usage and diction, syntax, organization, internal consistency, and numbers), tables and figures, units of measure and scientific terms, publishing requirements, copyright/publication ethics, and other areas [1]. Over $70 \%$ of the exam questions is related to English grammar, and they are not simple grammatical error questions; rather, they require the examinee to read and understand biomedical texts and to find the most suitable expressions. In addition, the exam also requires skills in research paper writing, such as creating tables/ figures, referencing, and understanding statistics and SI units, as well as knowledge of copyright and publication ethics.

In the case of the AMWA MWC program, the essential training curriculum is subdivided into gathering, evaluating, organizing, interpreting, and presenting [2]. In other words, AMWA requires knowledge related to researching, evaluating, organizing, interpreting and then publishing information in the form of a research paper or poster presentation. In comparison with BELS, which focuses on editing an article, the AMWA MWC demands an overall knowledge of the entire process of writing a research paper.

The AMWA Essential Skills Certificate program requires trainees to take eight different courses, including a mandatory publication ethics course, as well as core subjects such as English grammar, sentence structure, patterns, and punctuation; table and figure editing; statistics for medical writers and editors; and medical terminology. In contrast, the CSE Publication Certificate Program includes short courses for manuscript editors, including the technical aspects of manuscript editing, editing tables and figures, MS Word tips, communicating with authors, and publication ethics and legal issues [3].

According to our survey, a manuscript editor in Korea should not only be able to fulfill their own responsibilities, but should also be able to perform some of the work of a managing editor. In other words, a manuscript editor is expected to manage the editing process smoothly and to prepare journals to be indexed in databases abroad. If KCSE is to implement a 
science editing /

certification program based on examinations, the following should be tested: technical issues of manuscript editing (table and figure editing, searching and creating references, etc.), the units used in scientific papers, basic statistics, basic Korean and English grammar, publication ethics and copyright, understanding of international databases, and recent trends in journal publication.

KCSE is an organization including editors of journals dealing with all specialties within the fields of science and technology, making its subject range broader than that of BELS or AMWA. For this reason, the KCSE certification program may face difficulties in evaluating manuscript editors' knowledge of different subject areas. After certification, manuscript editors may have to pursue an independent study of the terminology related to a subject area in order to fulfill their duties as experts in that field.

In conclusion, the demand for certified manuscript editors is rising, and a certification program is needed. In particular, an examination-based certification program would appear to be the most efficient and suitable method for administering such a program.

\section{Conflict of Interest}

No potential conflict of interest relevant to this article was reported.

\section{Acknowledgments}

This research was supported by funding from the Korean Council of Science Editors (KCSE-2015-1).

\section{References}

1. Board of Editors in the Life Sciences (BELS). Become a board-certified editor [Internet]. Saint Paul, MN: BELS; c2015 [cited 2015 Nov 20]. Available from: http://www. bels.org/becomeeditor/index.htm

2. American Medical Writers Association (AMWA). Certification [Internet]. Rockville, MD: AMWA; c2015 [cited 2015 Nov 20]. Available from: http://www.amwa.org/certification

3. Council of Science Editors (CSE). CSE publication certificate program [Internet]. Wheat Ridge, CO: CSE; c2014 [cited 2015 Nov 20]. Available from: http://www.councilscienceeditors. org/resource-library/cse-publication-certificate-program

4. Korean Medical Library Association (KMLA). Medical librarian: introduction [Internet]. Seoul: KMLA [cited 2015 Nov 20]. Available from: http://www.kmla.or.kr

5. National Institute of Korean Language. Korean teacher [Internet]. Seoul: National Institute of Korean Language; [cited 2015 Nov 20]. Available from: https://kteacher.korean.go.kr 